\title{
Spontaneous Intracerebral Haematoma-II:Post-Operative Changes and Outcome of Burrhole Aspiration after Urokinase Mediated Clot Lysis
}

\author{
MN HOSSAIN $^{\mathrm{a}}$, S NABI ${ }^{\mathrm{b}}$, SS HOSSAIN ${ }^{\mathrm{c}}$
}

Summary:

Background: Treatments of intracerebral hematoma (ICH) are controversial and surgical interventions in spontaneous ICH are required and more accepted. Although advantage of neurosurgical intervention conservative treatment of ICH has not been established, recent reports have suggested favourable effects of blood clot removal after liquefaction by means of urokinase. Objectives: To study the intervention by and out come in without or with complications of Burrhole aspiration treatment after urokinase mediated clot lysis; Study Design : Prospective interventional study. Place and Duration of Study: Departments of Neurosurgery and Radiology \& Imaging, Dhaka Medical College Hospital, Dhaka, Bangladesh from July 2010 to December 2010; Materials \&Methods: A total of 30 Bangladeshi patients with spontaneous ICH (Age range: 40-75yrs, Mean age $\pm S D: 59.1 \pm 11.52$ years, Gender : 22 males, 8 females) full filling the criteria for spontaneous ICH were included in the study. The desired information relevant to the objectives were obtained and recorded carefully using a structured questionnaire; The Patients were treated with Burrhole aspiration after urokinase mediated lysis, evaluated for out come, complications and death and statistically analyzed ; Results: The results on delays of intervention ,types of intervention, doses of urokinase, post-operative

Introduction:

Literature on spontaneous intracerebral hematoma (ICH) have been reviewed in our preceeding article where age, gender distribution, precipitating factors, clinical

a. Dr. Mohammad Nazrul Hossain, Registrar, Dept. of Neurosurgery, Apollo Hospitals, Bashundhara Residential Area, Dhaka, Bangladesh

b. Dr. Shahryar Nabi, Assistant Professor of Radiology and Imaging, Dept of Radiology \& Imaging, Dhaka Medical College Hospital, Dhaka, Bangladesh

c. Prof. Dr. Sk. Sader Hossain, Professor and Head of Department, Department of Neurosurgery, Dhaka Medical College Hospital, Dhaka, Bangladesh

Address of Correspondence: Dr. Mohammad Nazrul Hossain, Registrar, Dept. of Neurosurgery, Apollo Hospitals, Bashundhara Residential Area, Dhaka-1229, Bangladesh. Mobile: 01819496333, Email: drmnh2003@yahoo.com

Received: 19 March, 2014 Accepted: 10 February, 2016 changes in haematoma volume, outcome with Glasgow outcome scale(GOS) and GOS at follow-up, complications and death were presented with statistical analyses and significance.The outcome and death were compared with various variables such as hypertension $(p<0.05)$, diabetes mellitus $(p<0.05)$ primary GOS $(P<0.05)$, site of hematoma $(p<0.05)$, volume of haematoma $(p<0.05)$, ventricular extension of hematoma $(p<0.05)$ and delay from ictus to intervention $(p<0.05)$. Conclusion : It was observed that early treatment (within 24 hours of occurance) by using minimally invasive technique and clot removal by urokinase mediated lysis can improve the consequences especially those with haematoma volume $<40 \mathrm{ml}$, lobar haematoma and without ventricular extension. Bad prognostic factors were increase of blood pressure, diabetes mellitus, GOS level $<8$, haematoma in the basal ganglia, ventricular extension of the haematoma volume $>\mathbf{4 0} \mathrm{ml}$ and delay in intervention. However, the present was conducted with 30 patients only and therefore, studies with larger number of patients are required to draw more meticulous and more definitive conclusions.

Key words: Intracerebral Haematoma, Burrhole Aspiration, Clot Lysis.

(J Bangladesh Coll Phys Surg 2016; 34: 64-75)

presentations, neurological observations and CT scan findings in our patients with spontaneous ICH were documented. Although treatments of ICH are controversial, surgical interventions in spontaneous ICH are required and more accepted ${ }^{1}$. Haematomas about 3 cm diameter and those causing hydrocephalus generally require surgical evacuation. The detailed account of back ground scientific literature was not repeated here, as it has been stated in our preceding article. ${ }^{2-21}$ The procedure of intervention by, and outcome of, Burrhole Aspiration after urokinase mediated clot lysis constitute the contents of the present article, i.e. Part- II of our study.

Materials and Methods:

Place \& period of study, subjects of study, inclusion \& exclusion criteria and data collection procedures were 


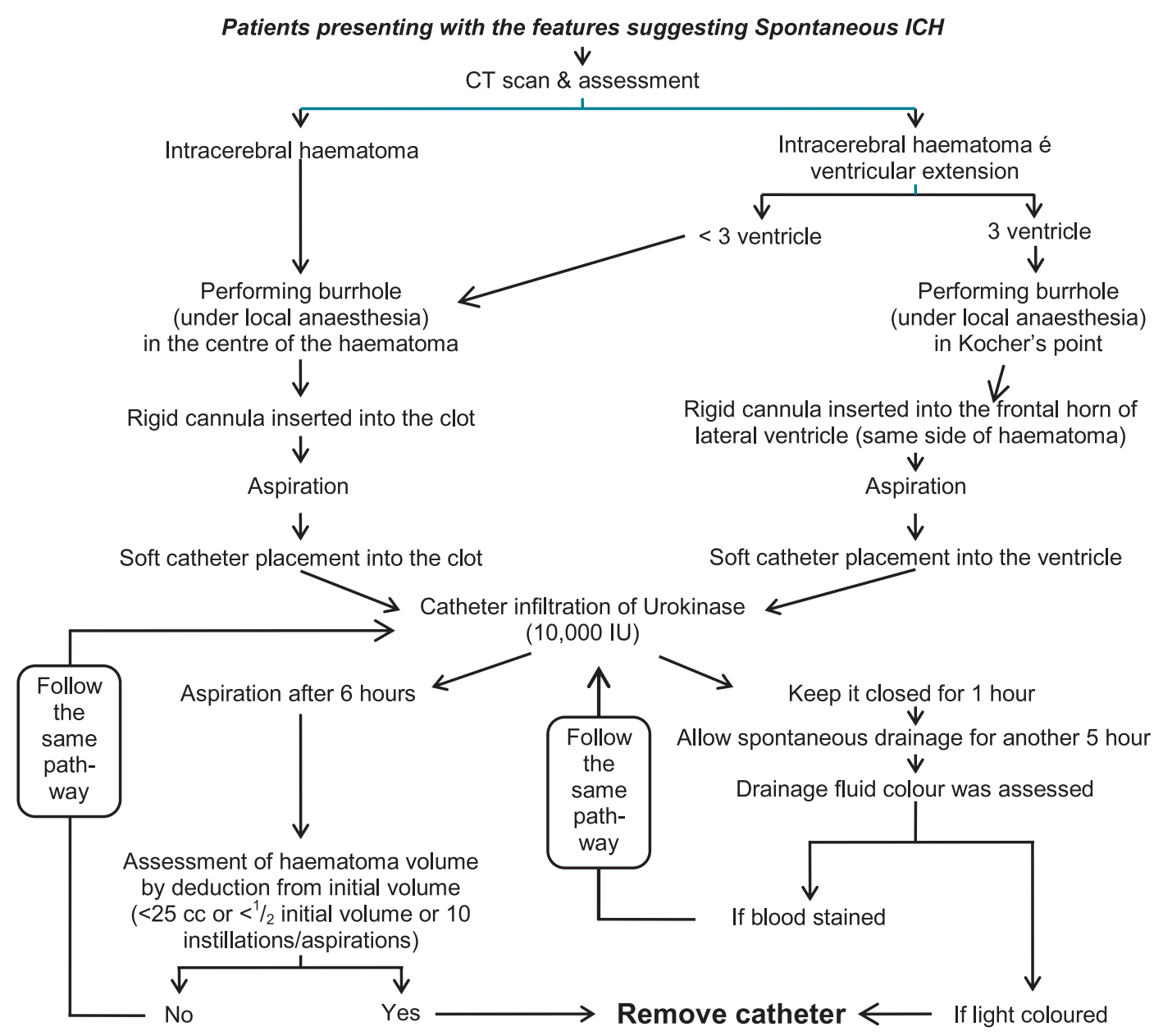

stated and explained in our preceding article ${ }^{1}$. ICH Diameter was measured from maximum diameter of axial section of CT scan; ICH Volume of haematoma was measured by modified ellipsoid formula by $ð / 6 \mathrm{ABC}$ which practically amounts to $1 / 2 \mathrm{ABC}$ as described 22 . The procedure of catheter placement was determined by the site of hematoma. Status of the patient during $3^{\text {rd }}$ post operative day (POD), at discharge and follow up $\left(30^{\text {th }}\right.$ POD) were recorded. Outcome was measured according to the modified Glasgow outcome scale (GOS) as suggested ${ }^{23}$. Favorable: GOS 3-5 Unfavourable: GOS 1 and 2 . The flow chart of the patients presenting with features of spontaneous ICH has been stated below :

\section{Statistical Analysis}

Data were analyzed with descriptive statistics, Chisquared () test and bi-variate analysis using computer aided statistical software SPSS win-17.The p value d" 0.05 was used as the level of significance.

\section{Results:}

\section{Interventions}

The results on delays of intervention, types of intervention and doses of urokeinase are presented in Table-1, Table-2, and Table-3 respectively. The post operative changes in haematoma volume and GOS and GOS at follow up are presented in Table-4,Figure-1 \& Table 5 respectively. The post- operative outcome( over all) complications, time of death and haemorrhage and death are stated in Figure-2 ,Table 6, Table-7 and Table-8 respectively.

The results on comparison of variables and outcome such as hypertension \& outcome, diabetes mellitus (DM) \& death, GOS \& outcome, site of haematoma and outcome, haematoma volume and outcome, ventricular extension and outcome and finally delay, site of haematoma and outcome are reported in Table 9a \& 9b, Table-10, Table- 
11a \& 11b, Table-12a \& 12b, Table 13a \& 13b, Table 14a \& $14 \mathrm{~b}$, and Table-15a \& $15 \mathrm{~b}$ respectively.

Delay: Table -1 shows that, on an average the delay from ictus to intervention was 41:43 hours with a range from 7.00 to 72.00 hours.

\section{Table-I}

Distribution of the patients by their delay from occurrence to intervention

\begin{tabular}{lcc} 
Time(Hours) & Frequemncy & Percent \\
\hline$\leq 24: 00$ & 14 & 46.7 \\
24:00-48:00 & 3 & 10.0 \\
$48: 00-72: 00$ & 13 & 43.3 \\
\hline Total & 30 & 100.0 \\
\hline
\end{tabular}

Mean \pm SD, $41.34 \pm 20.09$ Hours, Mode 48:00 Hours, Range 7:00 to 72:00 Hours

Type of intervention:_Table- 2 illustrate that catheter was inserted in the Ventricle in $2(6.6 \%)$ patients, in the centre of haematoma in $23(76.7 \%)$ patients and in both in $5(16.7 \%)$ patients..

\section{Table-II}

Distribution of the patients by the types of intervention

\begin{tabular}{lcc} 
Intervention & Frequency & Percent \\
\hline Catheter in the centre of & 23 & 76.7 \\
haematoma & & \\
Catheter in the Ventricle & 2 & 6.7 \\
Catheter in Both & 5 & 16.7 \\
\hline Total & 30 & 100.0 \\
\hline
\end{tabular}

Dose: Table- 3 shows that, on an average the patients received 5.7 doses (instillation and aspiration) of urokinase with a range from 2 to 10 times; Most of them $(14,46.7 \%)$ received 4 to 6 doses.

\section{Table-III}

Distribution of the patients by the doses of urokinase

\begin{tabular}{lcc} 
Dose & Frequency & Percent \\
\hline$\leq 3$ & 6 & 20.0 \\
$4-6$ & 14 & 46.7 \\
$>7$ & 10 & 33.3 \\
\hline Total & 30 & 100.0 \\
\hline
\end{tabular}

Mean \pm SD: $5.70 \pm 2.38$, Mode $: 4$,Range: 2 to 10 times

\section{Post-operative changes}

Change in haematoma :Table- 4 shows that, average haematoma volume on $3^{\text {rd }}$ POD was $7.67 \mathrm{ml}$. Only in a single patient, the volume in ventricle had increased.

\section{Table-IV}

Distribution of the patients by their changes in haematoma volume

\begin{tabular}{lccc}
$\begin{array}{l}\text { Volume of } \\
\text { haematoma }\end{array}$ & \multicolumn{2}{c}{ Ventricular extension } & Total \\
\hline Yes & $6 \mathrm{ml}$ & No & \\
$5-10 \mathrm{ml}$ & 4 & 4 & 10 \\
$>10 \mathrm{ml}$ & & 5 & 9 \\
More blood in ventricle & & 2 & 2 \\
\hline Total & 10 & 1 & 1 \\
\hline
\end{tabular}

Mean \pm SD: $7.67 \pm 4.531$, Mode: 10 , Range :2 to $20 \mathrm{~m}$

Change in GOS: Figure-1 explains that, more than onefourth of the patients $(8,26.67 \%)$ died before $3^{\text {rd }}$ POD (the first day for post-operative assessment of changes achieved through intervention). In a single (3.33\%) patient GOS decreased. Out of the remaining 21 cases, GOS increased 1 to 5 points.

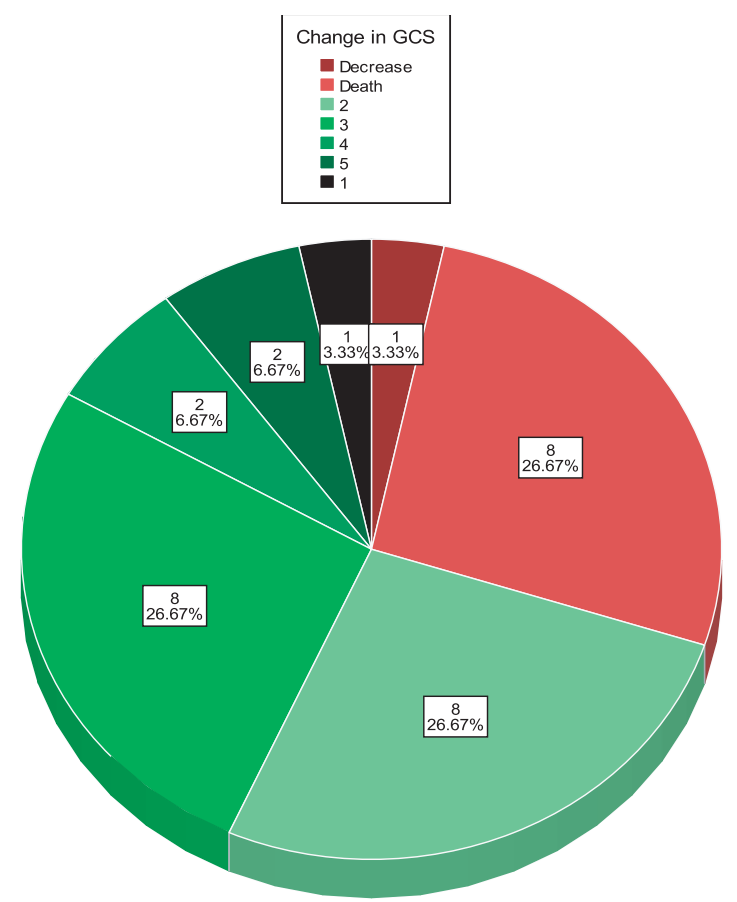

Fig.-1: Distribution of the cases by the change in GOS on $3^{\text {rd }}$ POD. 
GOS at follow up :Table 5 shows that, among the live patients, the GOS level had increased, i.e. on admission the level ranged from 6 to 11 and on $30^{\text {th }}$ POD the lowest level was 10.GCS and also, the average of GCS had increased from 8.00 (On admission) to 13 (On 30 $0^{\text {th }} \mathrm{POD}$ ). There is positive correlation between the changes of GCS level among the alive cases.

\section{Outcome, Complications \& Death}

Outcome of intervention overall : Figure-2 explains that near about three-fourth $(22,73.33 \%)]$ of the patients had unfavourable outcome; 14 (46.67\%) ‘Death' and 8 (26.67\%) 'Severe disability'. The remaining 8 had favourable outcome; 5 (16.67\%) 'Moderate disability' and $3(10.0 \%)$ 'Good recovery’.
Complications: Table - 6 illustrates that Iatrogenic pneumocephalous was the most $(5,16.7 \%)$ occurring complication; 15 (50\%) of the interventions were uncomplicated.

Time and cause of death: Table -7 shows that respiratory distress' was the cause of most (7, 23.33\%) deaths.

Haemorrhage and death :Table- 8 shows that involvement of different areas of the cerebral hemisphere had strong association in outcome, when only death was considered; i.e. only $14.3 \%$ patients with cortical haematoma died, on the contrary $85.7 \%$ patients with ICH in the basal ganglia with ventricular extension (3 or more ventricles) died.

\section{Table-V}

Distribution of alive cases by the GOS at follow - ups

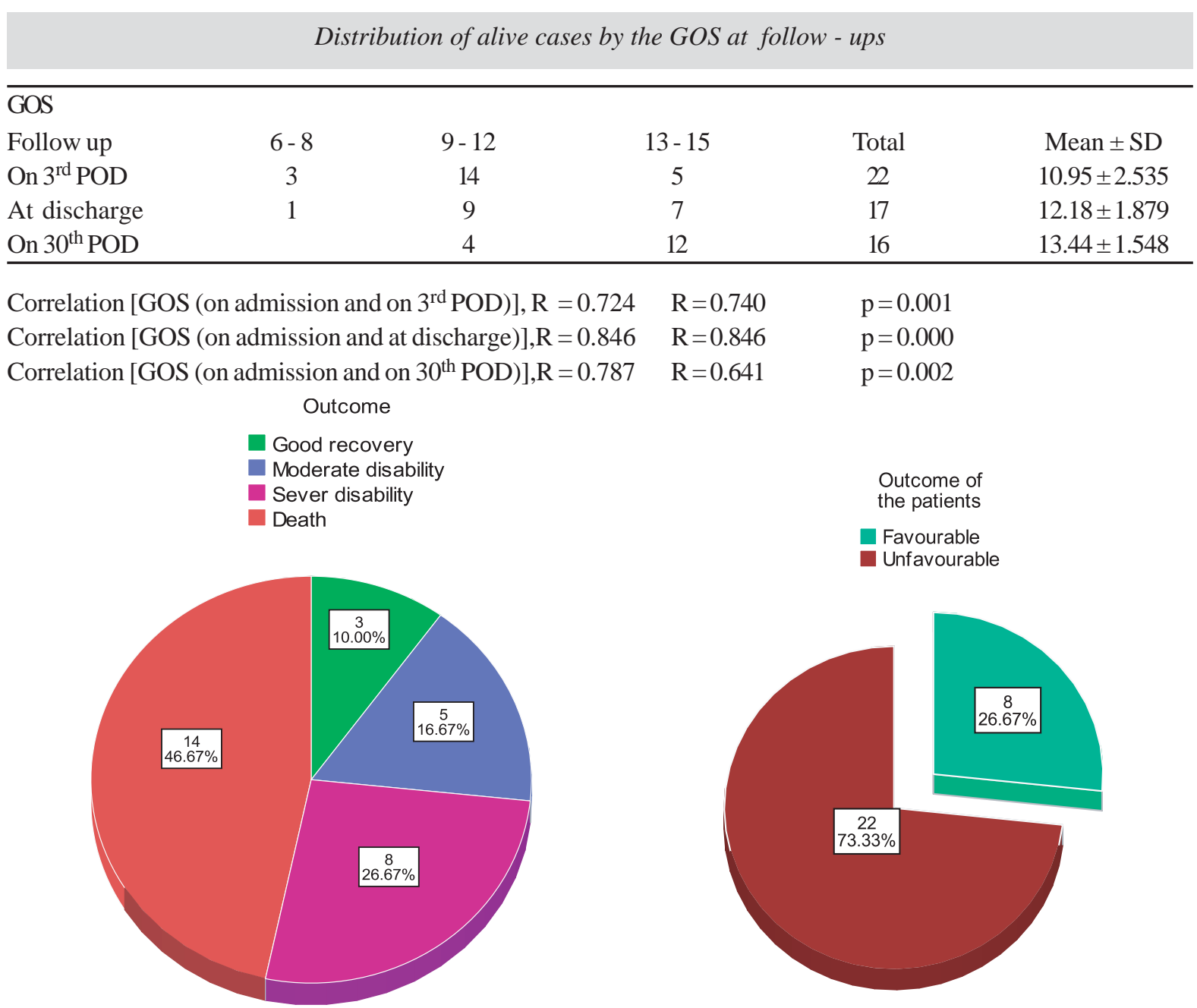

Fig.-2: Distribution of the patients by their outcome (according to GOS). 
Table-VI

Distribution of the cases by their postoperative complications

\begin{tabular}{|c|c|c|c|}
\hline \multicolumn{2}{|c|}{ Complications } & Frequency & Percent \\
\hline \multicolumn{2}{|c|}{ No complication } & 15 & 50.0 \\
\hline \multirow{5}{*}{ 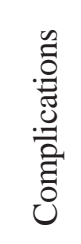 } & Pneumocephalous & 5 & 16.7 \\
\hline & Accidental catheter withdrawal & 2 & 6.7 \\
\hline & Aspiration pneumonia & 2 & 6.7 \\
\hline & Chest pain & 2 & 6.7 \\
\hline & Others (Meningitis, Re-stroke, Re-bleeding, Psychosis) & 4 & 13.3 \\
\hline \multicolumn{2}{|l|}{ Total } & 30 & 100.0 \\
\hline
\end{tabular}

Table-VII

Distribution of the cases by their time and cause of death

\begin{tabular}{|c|c|c|c|c|}
\hline \multirow[t]{2}{*}{ Cause of death } & \multicolumn{3}{|c|}{ Time of death } & \multirow[t]{2}{*}{ Total } \\
\hline & $\begin{array}{c}\text { Before } \\
3^{\text {rd }} \mathrm{POD}\end{array}$ & $\begin{array}{c}\text { Before } \\
\text { discharge }\end{array}$ & $\begin{array}{c}\text { Before } \\
30^{\text {th }} \mathrm{POD}\end{array}$ & \\
\hline Respiratory distress then death & 7 & & & 7 \\
\hline Sudden chest pain, then death & & 3 & & 3 \\
\hline Meningitis & & 1 & & 1 \\
\hline Aspiration pneumonia & 1 & & & 1 \\
\hline Re-bleeding & & 1 & & 1 \\
\hline 2nd stroke & & & 1 & 1 \\
\hline$\overline{\text { Total }}$ & 8 & 5 & 1 & 14 \\
\hline
\end{tabular}

Table-VIII

Distribution of the cases by their ICH and of death

\begin{tabular}{lcccc} 
Area of ICH & Number(n) & Death & Percentage (\%) & Fraction of death \\
\hline Cerebral cortex & 7 & 1 & 14.3 & 7.15 \\
Basal ganglia without ventricular extension & 6 & 3 & 50.0 & 21.43 \\
Basal ganglia ventricular extension (<3 ventricle) & 10 & 4 & 40.0 & 28.57 \\
Basal ganglia ventricular extension (e”3 ventricle) & 7 & 6 & 85.7 & 42.85 \\
\hline Total & 30 & 14 & 46.7 & 100 \\
\hline
\end{tabular}

\section{Variables and Outcome}

Hypertension and outcome: Table -9a shows , an inverse relation of blood pressure with outcome, i.e. with the increase of BP (both systolic and diastolic) GOS decreases'. Table-9b shows that atthough all the deaths were among those with high blood pressure, the difference in death in respect of hypertension was not statistically significant $\left(x^{2}=22.969, \mathrm{p}>0.05\right)$.
GOS and Outcome: Table 11a shows that outcome achieved depended on initial GOS (on admission). The incidence of death was higher in patients with lower GOS level group. All of the patients with 'good recovery' had a GOS of 9 to 12 and patients with 'moderate disability' had initial GOS more than 6. Table -11b shows the incidence of death among patient with primary GOS; it was significantly higher in patients with lower GOS on admission $\left(\mathrm{X}^{2}=3.519, \mathrm{p}<0.05\right)$. 


\section{Table- IX a}

Distribution of the cases by hypertension and outcome

\begin{tabular}{|c|c|c|c|c|c|c|c|}
\hline & & \multicolumn{5}{|c|}{ Outcome } & \multirow[t]{2}{*}{ Total } \\
\hline & & Death & $\begin{array}{c}\text { Persistent } \\
\text { vegetative } \\
\text { state }\end{array}$ & $\begin{array}{c}\text { Severe } \\
\text { disability }\end{array}$ & $\begin{array}{l}\text { Moderate } \\
\text { disability }\end{array}$ & $\begin{array}{c}\text { Good } \\
\text { recovery }\end{array}$ & \\
\hline \multirow{3}{*}{ 岕.号 } & Mild hypertension & & & 6 & 5 & 3 & 14 \\
\hline & Moderate hypertension & 6 & & 1 & & & 7 \\
\hline & Severe hypertension & 8 & & 1 & & & 9 \\
\hline & Total & 14 & & 8 & 5 & 3 & 30 \\
\hline
\end{tabular}

\section{Table-IX b}

Distribution of the cases by hypertension and death

\begin{tabular}{lccc} 
hypertension & \multicolumn{2}{c}{ Outcome } & Total \\
\cline { 2 - 4 } & Dead & Alive & 14 \\
\hline Mild & 0 & 14 & 16 \\
\hline Moderate to severe & 14 & 2 & 30 \\
\hline Total & 14 & 16 & \\
\hline
\end{tabular}

$\chi^{2}=22.969, \quad \mathrm{df}=\mathrm{p}<0.05$

DM and death; Table-10 shows that all the 7 (23.33\%) DM patients suffering from spontaneous ICH died.

Table-X

\begin{tabular}{|c|c|c|c|}
\hline \multicolumn{4}{|c|}{ Distribution of the patients by DM and death } \\
\hline \multirow[t]{2}{*}{$\mathrm{DM}$} & \multicolumn{2}{|c|}{ Death } & \multirow[t]{2}{*}{ Total } \\
\hline & Yes & No & \\
\hline Yes & 7 & 0 & 7 \\
\hline No & 0 & 0 & 0 \\
\hline Total & 7 & 0 & 7 \\
\hline
\end{tabular}

Table-XI a

\begin{tabular}{llccccc}
\multicolumn{7}{c}{ Distribution of the patients by their primary GOS and outcome } \\
\cline { 2 - 6 } GOS & Death & $\begin{array}{c}\text { Persistent } \\
\text { vegetative } \\
\text { state }\end{array}$ & $\begin{array}{c}\text { Sever } \\
\text { disability }\end{array}$ & $\begin{array}{c}\text { Moderate } \\
\text { disability }\end{array}$ & $\begin{array}{c}\text { Good } \\
\text { recovery }\end{array}$ & Total \\
\hline 6 to 8 & 11 & 4 & 1 & 3 & 16 \\
9 to 12 & 3 & 4 & 4 & 3 & 30 \\
\hline Total & 14 & 8 & 5 & 14 \\
\hline
\end{tabular}


Table-XI b

\begin{tabular}{|c|c|c|c|c|}
\hline \multicolumn{5}{|c|}{ Distribution of the patients by their primary GCS and death } \\
\hline & \multicolumn{2}{|c|}{ Outcome } & \multirow[t]{2}{*}{ Total } & \\
\hline & Dead & Alive & & \\
\hline \multirow[t]{2}{*}{ GCS } & 6 & 6 & 2 & 8 \\
\hline & $>6$ & 8 & 14 & 22 \\
\hline Total & 14 & 16 & 30 & \\
\hline
\end{tabular}

$\chi^{2}=3.519 \quad \mathrm{df}=1 \quad \mathrm{p}=0.05$

Site of haematoma and outcome :Table-12a shows that outcome of haematoma in the basal ganglia was not good, as out of 23 (76.67\%) haematoma 13 (43.33\%) died. All 3 'good recovery’ had cortical haematoma. Table- $12 \mathrm{~b}$ shows that the death rate was higher in patients with haematoma in the basal ganglia which was statistically significant $(\mathrm{p}=0.05)$.

Hematoma volume and outcome: Table-13a indicates that outcome of large haematoma was not good; death rate was high among patients with larger haematoma. All 3 'good recovery' was with smaller haematoma. Table- 13b shows that, the difference between death and haematoma volume was statistically significant $\left(\chi^{2}=0.117, \mathrm{p}<0.05\right)$.

Ventricular extension and outcome :Table-14a shows that the ratio of death was higher among patients with ventricular extension of the haematoma as 10 (33.33\%) died out of $18(60.0 \%)$ patients were with ventricular extension. All the patients with 'good recovery' did not have any ventricular extension of the haematoma.

Table14b shows that the difference in death among patients with ventricular extension of haematoma was statistically significant $(\mathrm{p}<0.05)$

Delay, site haematoma and outcome: Table 15a explains that the cortical haematoma showed time dependant outcome, 'the earlier the intervention the better the recovery. The single death in patient suffering from ICH in the cortex, had a 72 hours delay from incidence to start of intervention. Table -15b shows that there was statistically significant difference in death and interval between ictus and intervention ( $\mathrm{p}<0.05)$; Better results were shown with early intervention

Table-XII a

\begin{tabular}{llccccc} 
& \multicolumn{5}{c}{ Distribution of the cases by their site of haematoma and outcome } \\
Location of & \multicolumn{5}{c}{ Outcome } & Total \\
\cline { 2 - 6 } & Death & $\begin{array}{c}\text { Persistent } \\
\text { vegetative state }\end{array}$ & $\begin{array}{c}\text { Sever } \\
\text { disability }\end{array}$ & $\begin{array}{c}\text { Moderate } \\
\text { disability }\end{array}$ & $\begin{array}{c}\text { Good } \\
\text { recovery }\end{array}$ & \\
\hline Basal ganglia & 13 & 7 & 3 & 3 & 23 \\
$\begin{array}{l}\text { Cortical } \\
\text { haematoma }\end{array}$ & 1 & 1 & 2 & 3 & 30 \\
\hline Total & 14 & 8 & 5 & 3 & \\
\hline
\end{tabular}

Table-XII b

\begin{tabular}{l} 
Distribution of the cases by the location of haematoma and death \\
\cline { 3 - 5 } \\
\cline { 3 - 5 }
\end{tabular}

$\chi^{2}=3.846, \quad \mathrm{df}=1 \quad \mathrm{p}=0.05$ 
Table-XIII a

Distribution of the patients by their volume of the haematoma and outcome

\begin{tabular}{|c|c|c|c|c|c|c|c|}
\hline & & & Outcome & & & & Total \\
\hline & Death & $\begin{array}{c}\text { Persistent } \\
\text { vegetative state }\end{array}$ & $\begin{array}{c}\text { Sever } \\
\text { disability }\end{array}$ & $\begin{array}{l}\text { Moderate } \\
\text { disability }\end{array}$ & $\begin{array}{c}\text { Good } \\
\text { recovery }\end{array}$ & & \\
\hline & $\leq 20 \mathrm{ml}$ & & 2 & 2 & 1 & 5 & \\
\hline 胥 & $21-40 \mathrm{ml}$ & & 5 & 3 & 2 & 1 & 11 \\
\hline 킁 己 & $41-60 \mathrm{ml}$ & & 6 & 3 & 2 & 1 & 12 \\
\hline$>2$ & $>60 \mathrm{ml}$ & & 1 & & 1 & & 2 \\
\hline Total & 14 & & 8 & 5 & 3 & 30 & \\
\hline
\end{tabular}

Table-XIII b

Distribution of the cases by the volume of haematoma and death

\begin{tabular}{|c|c|c|c|c|}
\hline & & & & Total \\
\hline & & Dead & Alive & \\
\hline 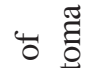 & $\leq 40 \mathrm{ml}$ & 7 & 9 & 16 \\
\hline is 壳 & $>40 \mathrm{ml}$ & 7 & 7 & 14 \\
\hline & Total & 14 & 16 & 30 \\
\hline
\end{tabular}

$\chi^{2}=0.117 \quad \mathrm{df}=1, \quad \mathrm{p}<0.05$

Table-XIV a

Distribution of the cases by their ventricular extension of haematoma and outcome

\begin{tabular}{|c|c|c|c|c|c|c|}
\hline & & & Outcome & & & Total \\
\hline & Death & $\begin{array}{c}\text { Persistent } \\
\text { vegetative state }\end{array}$ & $\begin{array}{c}\text { Sever } \\
\text { disability }\end{array}$ & $\begin{array}{l}\text { Moderate } \\
\text { disability }\end{array}$ & $\begin{array}{c}\text { Good } \\
\text { recovery }\end{array}$ & \\
\hline 흐 훙 & No & 4 & 1 & 4 & 3 & 12 \\
\hline 䓌 & Yes & 10 & 7 & 1 & & 18 \\
\hline Tota & & 14 & 8 & 5 & 3 & 30 \\
\hline
\end{tabular}

Table-XIVb

Distribution of the cases by their ventricular extension of haematoma and death

\begin{tabular}{|c|c|c|c|c|}
\hline & & & & Total \\
\hline & & Dead & Alive & \\
\hline 흘 & No & 4 & 8 & 12 \\
\hline$\stackrel{\overrightarrow{0}}{\stackrel{\overrightarrow{0}}{\alpha}}$ & Yes & 10 & 8 & 18 \\
\hline Total & & 14 & 16 & 30 \\
\hline
\end{tabular}


Table-XV a

Distribution of the patients by their outcome with site of haematoma and delay from ictus to intervention

\begin{tabular}{l}
$\begin{array}{l}\text { Site of } \\
\text { haematoma }\end{array}$ \\
\hline
\end{tabular}

Table-XVb

\begin{tabular}{|c|c|c|c|c|}
\hline \multicolumn{5}{|c|}{ Distribution of the cases by their delay and death } \\
\hline & & \multicolumn{2}{|c|}{ Outcome } & \multirow[t]{2}{*}{ Total } \\
\hline & & Dead & Alive & \\
\hline \multirow[t]{2}{*}{ Delay } & $\leq 24 \mathrm{hrs}$ & 6 & 8 & 14 \\
\hline & $>24 \mathrm{hrs}$ & 8 & 8 & 16 \\
\hline Total & 14 & 16 & 30 & \\
\hline
\end{tabular}

\section{Discussion:}

The age - gender information, precipitating factors , clinical presentations, neurological observation and CT scan findings in spontaneous ICH were presented and discussed in our previous article (Part-I $)^{1}$.In the present article (Part -II), the surgical intervention by, and outcome of, Burrhole aspiration after urokeniase mediated clot lysis were presented and discussed as part -II of our study findings.

On an average, the delay from ictus to intervention was 41:43 hours with a range from 7:00 to 72:00 hours. Among our patients, 47(49\%) were operated within 24 hours, 21 (22\%) between 24 to 48 hours, 14 (15\%) between 48 to 72 hours and 13 (14\%) between 3 to 7 days. Only 01 patient was operated beyond 7 days after ictus ${ }^{24}$. Our27 (67.50\%) patient's presented within 2 days and $13(32.50 \%)$ patients attended after 2 days. $)^{19,25 .}$

Catheter in the Ventricle was inserted in 2 (6.6\%) patients. Catheter was placed in the centre of the haematoma in
23 (76.7\%) patients and the remaining 5 (16.7\%)] were benefited by both centre of haematoma and ventricle procedures. On an average, the patients received about 6 doses (instillation \& aspiration) of urokinase with a range from 2 to 10 times. Most of them [14 (46.7\%)] received 4 to 6 doses. Out of total 40 patients with $\mathrm{ICH}$, in 25(62.5\%) patients Burrhole aspiration of haematoma was done, in $8(20.00 \%)$ patients external ventricular drainage, in 5( $12.50 \%)$ patients craniectomy and decompression, in 2 patients (5.0\%) cranicctomy and evacuation of haematoma was done ${ }^{19,26}$ Out of total 29 patients with ICH, in $8(27.56 \%)$ patients external ventricular drainage, in 7( $24.13 \%)$ patient's craniectomy and decompression, in 14(48.27\%) patient's craniotomy and evacuation of haematoma was done ${ }^{27}$.Out of total 30 patients with ICH, in 13 (43.3\%) patients craniotomy and evacuation of haematoma was done, in 13 (43.3\%) patients Burrhole aspiration of haematoma was done, in 3 (10\%) patients craniectomy and evacuation of 
haematoma was done, in 1 (3.3\%) patient external ventricular drainage (EVD) was done 28,29 .

Average haematoma volume on $3^{\text {rd }}$ POD was $7.67 \mathrm{ml}$. Only in 1(one) patient, the volume in ventricle had increased. a mean ICH volume of $65.4 \mathrm{ml}$ (SD $28.1 \mathrm{ml}$ ) on day 1 , $47.5 \mathrm{ml}$ (SD $30 \mathrm{ml}$ ) on day 3 , and $44.4 \mathrm{ml}$ (SD 30.7 $\mathrm{ml})$ on day $7^{30}$.The average haematoma volume after operation was $7.60 \mathrm{ml}$. With each dose of urokinase the average haematoma volume decrease varied in individuals from as less as $2.0 \mathrm{ml}$ to $15.0 \mathrm{ml}$. . In a single (3.33\%) patient GOS decreased. Out of the remaining 21 cases, GOS increased 1 to 5 points. In most cases [9 (30.0\%)], the increase was by 3 points, followed by 2 points in 7 (23.33\%) cases and 4 in $3(10.0 \%)$ cases. Motor strength of all the live patients gradually increased except only a single case who eventually died.

More than one-fourth of the patients [8 (26.67\%)] died before $3^{\text {rd }}$ POD (the first day for post-operative assessment of changes achieved through intervention). In a single (3.33\%) patient GOS decreased. Out of the remaining 21 cases, GOS increased 1 to 5 points. Again, among the live patients the GOS level had increased, i.e. on admission the level ranged from 6 to 11 and on $30^{\text {th }}$ POD the lowest level was 10. GOS and also, the average of GOS, had increased from 8.00 (On admission) to 13.44 (On $30^{\text {th }}$ POD). There is positive correlation between the changes of GOS level among the alive cases. \{Correlation [GOS (on admission and on $3^{\text {rd }} \mathrm{POD}$ )] = 0.724; $\mathrm{R}=0.740$ ( $\mathrm{p}=0.001$ ); Correlation [GOS (on admission and at discharge $)]=0.846 ; \mathrm{R}=0.846(\mathrm{p}=$ 0.000 ) and Correlation [GOS (on admission and on $30^{\text {th }}$ $\mathrm{POD})]=0.787 ; \mathrm{R}=0.641(\mathrm{p}=0.002)\}$.

About three-fourth [22 (73.33\%)] of the patients had unfavourable outcome; 14 (46.67\%) 'Death' [among them 1 (7.14\%) patient from lobar haematoma, 3 (21.42\%) patients from basal ganglia without ventricular extension, 4 (28.57\%) patients from basal ganglia with less than three ventricular extension and remaining 6 (42.82) patients from basal ganglia with more than three ventricular extension and 8 (26.67\%) 'Sever disability' ['(one from lobar(12.5\%), six from basal ganglia with less than three ventricle extension (75.0\%) and one from basal ganglia with more than three ventricle extension(12.5\%)]. The remaining 8 had favourable outcome; 5 (16.67\%) 'Moderate disability’ [two from lobar (40.0\%) and 3 (60.0\%) basal ganglia without ventricular extension] and 3 (10.0\%) ‘Good recovery’(all from lobar haematoma). In basal ganglia mortality is 25\%, severe disability was $50 \%$ and moderate disability was $25 \%^{31}$. In lobar haematoma mortality was $41.2 \%$, severe disability was $35.5 \%$ and moderate disability was $23.5 \%$. In Basal ganglia with ventricular extension, mortality was $100 \%$ and lobar haematoma with ventricular extension mortality was $71.4 \%$.

Of the interventions 50\% (15) were uncomplicated. Iatrogenic pneumocephalous was the most [5 (16.7\%)] occurring complications, 2 (6.7\%) individuals each had 'accidental catheter withdrawal', aspiration pneumonia and chest pain. Other complications like, meningitis, restroke, re-bleeding, psychosis accounted for a single (3.3\%) case. Near about half [14 (46.67\%)] of the patients died. Out of the deaths, most [8 (26.67\%)] occurred before $3^{\text {rd }}$ POD ( $1^{\text {st }}$ date for assessment of outcome). 'Respiratory distress' was cause of 7(50.0\%) deaths. Myocardial infraction was responsible for 3 (21.48\%) deaths. Re-bleeding, meningitis, aspiration pneumonia and re-stroke were the cause of remaining 4 (28.52\%) deaths. Jin et al reported that nine patients (16.9\%) died before hospital discharge (one from cardiac problems and eight from respiratory failure). ${ }^{18}$

Involvement of different areas of the cerebral hemisphere had strong association in outcome when only death was considered, i.e. only $14.3 \%$ patients with cortical haematoma died. On the contrary, $85.7 \%$ patients with ICH in the basal ganglia with ventricular extension (3 or more ventricles) died. An inverse relation of blood pressure with outcome, ie "with the increase of BP (both systolic and diastolic) GOS decreased. Although all the deaths were among those with 'moderate to high blood pressure', the difference in death in respect of hypertension was not statistically significant ( $\mathrm{p}>0.05$ ). All the 7 (23.33\%) diabetic patients suffering from spontaneous ICH died. Outcome achieved depended on initial GCS (on admission). The ratio of death was higher in patients with lower GOS level group. All of the patients with good recovery had a GOS of 9 to 12 and patients with 'moderate disability' had initial GOS more than 6. Death rate was higher in patients with lower GOS on admission; the difference was statistically significant $(p<0.05)$. Outcome of haematoma in the basal ganglia was not good, as out of 23 (76.67\%) haematoma 13 (43.33\%) died. All 3 good recovery had cortical haematoma. Although the death rate was higher 
in patients with haematoma in the basal ganglia, the difference was not statistically significant; ( $p>0.05$ ). Outcome of large haematoma volume was not good; death rate was high among patients with larger haematoma ( $>40 \mathrm{ml})$. All 3 good recovery was with small volume of haematoma ( $<40 \mathrm{ml})$. The difference was statistically significant between death and haematoma volume. $(\mathrm{p}<0.05)$. The ratio of death was higher among patients with ventricular extension of the haematoma as 10 (33.33\%) died out of 18 (60.0\%) patients with ventricular extension. On the contrary, only 4 (13.33\%) died among the 12 (40.0\%) cases without ventricular extension. The death rate was 1.67 times higher in patients with ventricular extension. All the patients with good recovery did not have any ventricular extension of the haematoma. The difference in death among patients with ventricular extension of haematoma was statistically significant; $p<0.05$. The cortical haematoma showed time dependant outcome, 'the earlier the intervention the better was the recovery'. The single death in patient suffering from ICH in the cortex had a 72 hours delay from incidence to start of intervention. There was statistically significant difference in death and interval between ictus and intervention indicating better results with early intervention $(\mathrm{p}<0.05)$. Outcome of study by Jin et al, was - at discharge, 25 patients (47\%) had achieved good recovery (17patients GOS 3, 6 patients GOS 4 and 2 patients GOS 5), and 19 patients $(35.8 \%)$ remained vegetative (GOS 2) ${ }^{18,32,33}$. At 6 months follow up, 29 patients (55\%) had achieved good recovery (17 patients GOS 3, 8 patient GOS 4, and 4 patients GOS 5) and 15 patient ,(28.3\%) remained vegetative (GOS 2).

However the current study was conducted among 30 patients only, not a large study to draw a definitne conclusion. Study of Spontaneous ICH in the perspective of the objective of the study was rare, causing difficulty to compare the findings to other research findings. Patients came from all corners of the country after referral from local primary and secondary hospitals, even from some tertiary hospitals. So, the delay in occurrence to intervention took its toll as death of the patients or severe disability. Patients had their last follow up on $30^{\text {th }}$ POD, very short duration to overcome neurological deficits. If the duration were longer, the condition of the live patients would have been better ideally. It meant that larger study including more patients with longer postoperative follow-up and minimal delay between the occurrence of ICH and intervention should be done to draw more definitive conclusion.

In Conclusion, early treatment (within 24 hours of occurrence) by using minimally invasive technique and clot removal by urokinase mediated clot lysis can improve the consequences especially those with haematoma volume $<40 \mathrm{ml}$, lobar haematoma and without ventricular extension. Bad prognostic factors were increase of BP (both systolic and diastolic), diabetes mellitus, GOS level <8, haematoma in the basal ganglia, ventricular extension of the haematoma volume $>40 \mathrm{ml}$ and delay in intervention.

\section{Acknowledgements:}

The authors would like to thank and gratefully acknowledge Dr. K. A. Jhuma for valuable suggestions and help during preparation of the manuscript.

\section{References:}

1. Hossain MN, Hossain SS, Nabi S .Spontaneous intracerebral Haematoma-I; Socioeconomic information, precipitating factors, clinical presentations, neurological observations and CT scan findings. J of the College of Physicians and Surgeons Pakistan; 2013 (submitted).

2. Ojemann RG \& Heros RC. Spontaneous brain hemorrhage. Stroke1983; 14(4): 468-75.

3. Siddique MS \& Mendelow AD. Surgical treatment of intracerebral hemorrhage. Br Med Bull 2000; 56(2): 444-56.

4. Lejeune JP \&Thines L. Neurosurgical management of spontaneous cerebral hemorrhage. J Neuroradiol 2003; 30(5): 332-5.

5. Escosa BM \& Sola RG. Surgical indications in non traumatic intracerebral hemorrhage. Rev Neurol 2001; 32(11): 1060-2.

6. Unwin DH, Batjer HH and Greenlee RGJR. Management controversy: medical versus surgical therapy for spontaneous intracerebral hemorrhage. Neurosurg Clin $\mathrm{N}$ Am 1992; 3: 533-537.

7. Kingman TA, Mendelow AD, Graham DI \& Teasdale GM . Experimental intracerebral mass: description of model, intracranial pressure changes and neuropathology. J Neuropathol Exp Neurol 1988; 47: 128-137.

8. Chambers IR, Banister K\& Mendelow AD. Intracranial pressure within a developing intracerebral haemorrhage. Br J Neurosurg 2001; 15: 140-141.

9. Zazulia AR, Diringer MN, Videen TO, Adams RE, Yundt K, Aiyagari V, Grubb RLR, \& Powers WJ, Hypoperfusion without ischemia surrounding acute intracerebral 
hemorrhage. J Cereb Blood Flow Metab .2001 ;21: 804-810.

10. Zazulia AR, Diringer MN, Derdeyn CP\& Powers WJ. Progression of mass effect after intracerebral hemorrhage. Stroke 1999; 30: 1167-1173.

11. Lee KR, Kawal N, Kim S, Sagher O\& Hoff JT. Mechanisms of edema formation after intracerebral hemorrhage: effects of thrombin on cerebral blood flow, blood-brain barrier permeability and cell survival in a rat model. J Neurosurg 1997; 86: 272-278.

12. Prasad K\& Shrivastava A. Surgery for primary supratentorial intracerebral haemorrhage. Cochrane Database Syst Rev2000; 2: CD000200.

13. AuerLM, Ascher PW, Heppner F, Ladurner G, Bone G\& Lechner H. Does acute endoscopic evacuation improve the outcome of patients with spontaneous intracerebral hemorrhage? Eur Neurol 1985; 24: 254-261.

14. Zucacrello M, Andaluz N\& Wagner KR. Minimally invasive therapy for intracerebral hematomas. Neurosurg Clin N Am 2002; 13(3): 349-54.

15. MillerDW, Barnett GH, Kormos DW\& Steiner CP. Stereotactically guided thrombolytic of deep cerebral hemorrhage: preliminary results. Cleve Clin J Med 1993; 60: 321-324.

16. Montes JM, Wong JH, Fayad PB \& Awad IA. Stereotactic computed tomographic-guided aspiration and thrombolysis of intracerebral hematoma: protocol and preliminary experience. Stroke 2000; 31: 834-840.

17. Rohde V, Rohde I, Reinges MH, Mayfrank L\& Gilsbach JM. Frameless stereotactically guided catheter placement and fibrinolytic therapy for spontaneous intracerebral hematomas: technical aspects and initial clinical results. Minim Invasive Neurosurg 2000; 43: 9-17.

18. Jin SC, Hwang SK, Cho DS, Kim SH\& Park DB. . Urokinase Thrombolysis for Nonaneurysmal Spontaneous Intraventricular Hemorrhage. J Korean Neurosurg Soc 2005;38 : 281-286.

19. Das S. MS (Neurosurgery thesis). Role of surgery in primary spontaneous intracerebral haemorrhage- Analysis Of early outcome of surgery in relation to site and size of haemorrhage; BSMMU, Dhaka, Bangladesh; April 2004.

20. Rahman A. MS(Neurosurgery thesis) To compare the outcomes between surgical and medical treatment of spontaneous supratentorial intracerebal haemorrahge and also to compare the outcomes according to Glasgow Coma Scale (GCS), Glasgow outcome scale (GOS), Modified
Rankin Scale (MRS) and mortality between two groups; CMC,Chittagong, Bangladesh, June 2008.

21. ISLAM, T.K.M. MS(Neurosurgery thesis) Analysis Of early outcome of surgery in relation to preoperative Glasgow coma scale (GCS) score and volume of haematoma; DMC, Dhaka, Bangladesh; sep 2010

22. Urokinase. http://en.wikipedia.org/wiki/urokinase (modified on 24 september 2010 at 23.10)

23. Manno EM, Atkinson JLD, Fulgham JR \& Wijdicks EFM.Emerging medical and surgical management strategies in the evaluation and treatment of intracerebral Hemorrhage, Symposium on cerebrovascular Disease. Mayo clin proc.2005 march; 80: 420-433. URL:http:// enotes.tripod.com/ich 2005.htm

24. PAI SB, Varma RG, Parthiban JKBC.. Keyhole craniotomy in the surgical management of spontaneous intracerebral hematoma. Neurology Asia 2007;12: 21 - 27.

25. Kazui S, Minematsu K, Yamamoto H, Sawada T, Yamaguchi T. Predisposing factors to enlargement of spontaneous intracerebral hematoma. Stroke.1997; 28: 2370-5.

26. Kazul S, Naritomi H, Yamamoto H, Sawada T\& Yamaguchi T. Enlargement of spontaneous intracerebral hemorrhage: incidence and time course. Stroke 1996; 27:1783-7.

27. Mayer SA, Sacco RL, Shi T\& Mohr JP. Neurologic deterioration in noncomatose patients with supratentorial intracerebral hemorrhage. Neurology1994; 44:1379-84.

28. Mutlu N, Berry RG\& Alpers BJ,.Massive cerebral hemorrhage: clinical and pathological correlations. Arch Neurol 1963;8 :644-61.

29. Nath FP, Jenkins A, Mendlow AD, Graham DI \& Teasdale GM. 1986. Early hemodynamic changes in experimental intracerebral hemorrhage. J Neurosurg 1986;65:697-703.

30. Teernstra OPM, Evers SMAA, Lodder J,\& Leffers P. Stereotactic Treatment of Intracerebral Hematoma by Means of a Plasminogen Activator. Stroke.2003; 34:968974.

31. Tanaka A, Yoshinaga S, Nakayama Y, Kimura M \& Tomonaga M. Cerebral blood flow and clinical outcome in patients with thalamic hemorrhages: a comparison with putaminal hemorrhages. J Neurol Sci 1996 ;144:191-7.

32. Wagner KR, Xig G, Hua Y, et al. Lobar intracerebral hemorrhage model in pigs: rapid edema development in perihematomal white matter. Stroke 1996;27:490-7.

33. Ropper AH \& Gress DR Computerized tomography and clinical features of large cerebral hemorrhages. Cerebrovasc Dis $1991 ; 1: 38-42$. 